Brit. Heart J., 1964, 26, 554.

\title{
FAST-CONDUCTING FIBRES IN THE MITRAL VALVE
}

\author{
BY \\ T. H. WILLIAMS* \\ From The Department of Anatomy, The University, Manchester 13 \\ Received January 31, 1964
}

While investigating the innervation of the atrio-ventricular valves in several mammalian species (Williams, 1964), it was found that a small number of heavily myelinated fibres (diameter 6-8 $\mu$ ) were present in the mitral valve of the guinea-pig (Fig. 1A): these could be demonstrated clearly by a number of techniques, including osmium tetroxide staining, Champy's osmium tetroxide-zinc iodide method (1959), and silver impregnation methods. The myelinated fibres could also be distinguished using a modification (Coupland and Holmes, 1957) of Koelle and Friedenwald's (1949) process for localizing acetylcholinesterase activity, although in the normal animal these fibres do not stain darkly by this method and may therefore not be rich in the enzyme.

In company with numerous beaded nerve fibres, each of the myelinated fibres traversed a valve cusp from its attached margin to a chorda tendinea. The thick nerve fibre, or its branches, could be traced down the chorda to the papillary muscle into which it passed. The exact terminations of these fibres have not yet been defined.

The location within the mitral valve of these fast-conducting myelinated fibres is of physiological and clinical interest, and so it was decided to probe their extracardiac course by using degeneration experiments.

\section{MATERIALS AND METHODS}

Studies were carried out on 26 healthy young adult guinea-pigs, since appearances suggestive of axonal degeneration are common in the valves of older animals (Williams, 1964). They were divided into two equal groups, for control and for experimental purposes. Operations were done on 15 guinea-pigs, some under chloralose-urethane and others under "nembutal" anæsthesia. Of these, 3 were allocated for unilateral cervical sympathectomy and stellatectomy, 6 for unilateral vagotomy below and 4 above the inferior vagal ganglion, while the remaining 2 were operative controls for sympathectomy and vagotomy respectively. A survival time of approximately three days was allowed after each operation.

Tissues from both control and experimental series were processed in exactly the same fashion. The hearts were excised at death, and as soon as the ventricular chambers had been opened and rinsed with cold isotonic saline the mitral and tricuspid valves were infiltrated from the regions of their attached margins with hyaluronidase solution (Williams, 1962). This last procedure was undertaken with the aim of depolymerizing tissue mucopolysaccharides and thereby facilitating the penetration of the fixative and incubating solutions. Ten minutes later the hearts were placed in cold formol saline which had been saturated with calcium carbonate. After two hours' fixation, the valves were dissected free with minimal trauma. They were then placed on clean slides and allowed to dry thoroughly (about two hours at room temperature).

A histochemical method for localizing cholinesterase in neural elements was employed to demonstrate degenerative changes in the cuspidal nerve fibres (Williams, 1963a), the slides being incubated in a medium containing acetylthiocholine as substrate. After six hours at $37^{\circ} \mathrm{C}$., and at intervals thereafter, the preparations were examined under the staining microscope until nerve bundles were readily distinguishable. They were then washed in de-ionized water for 10 minutes, treated with dilute ammonium sulphide solution

* Now at Dept. of Anatomy, Harvard University, Boston, Mass., U.S.A. 


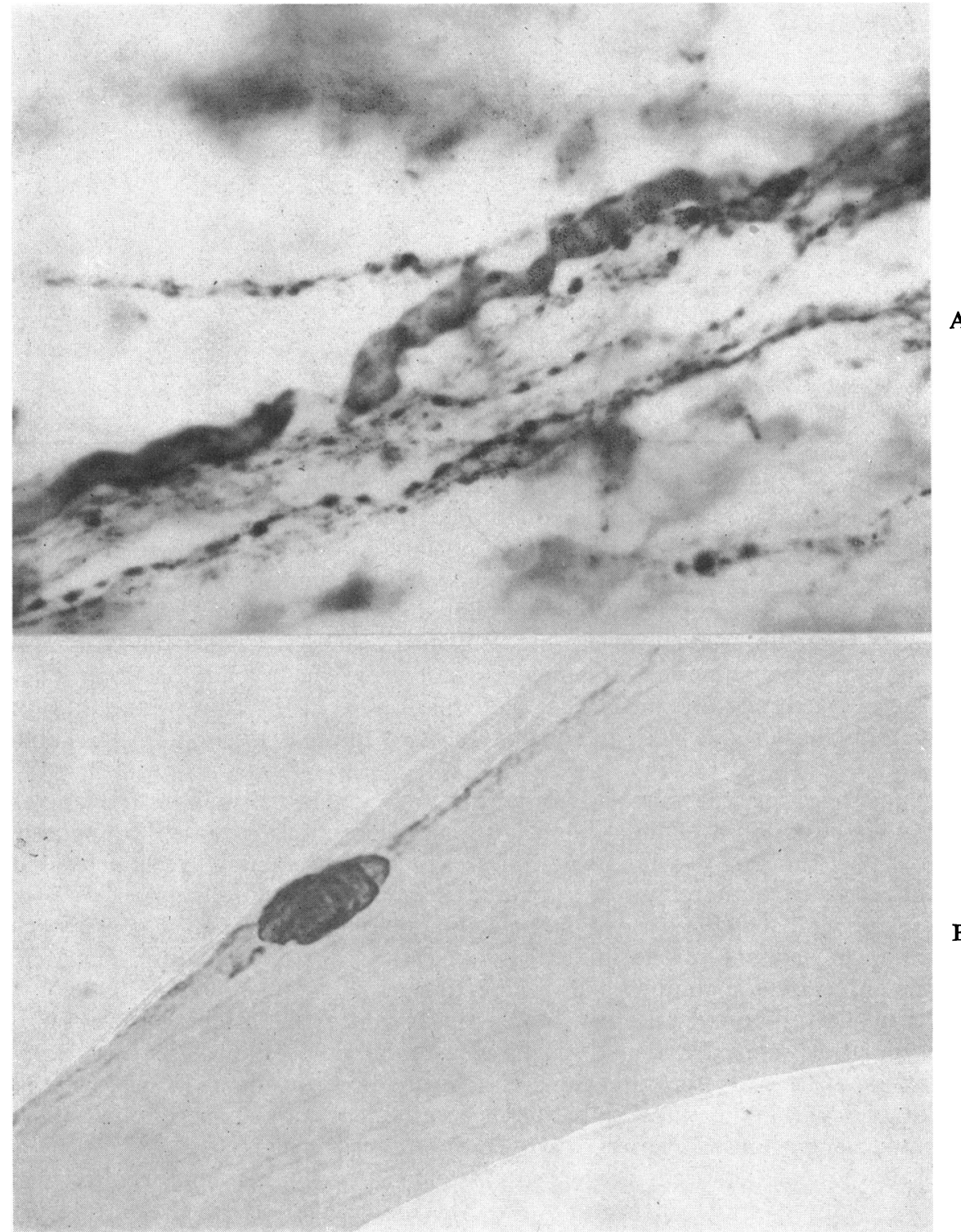

A

B

FIG. 1.-(A) Myelinated nerve fibre of guinea-pig, diameter about $7 \mu$, in transit through a mitral valve cusp. Cuspidal nerve fibres of this size are few in number, and typically one is associated with many beaded nerve filaments. (Osmium tetroxide. $\times 700$.) (B) Acetylcholinesterase-positive vesicle $(35 \mu \times 15 \mu)$, in a chorda tendinea of mitral valve of guinea-pig, three days after vagotomy carried out above the inferior vagal ganglion. The vesicle is believed to be a "digestion chamber", resulting from degeneration of a myelinated axon. Remnants of adjacent parts of this axon, showing some enzyme activity, can be seen. (Thiocholine. $\times 520$.)

until the white reaction product turned brown, dehydrated, cleared, and mounted in Canada balsam dissolved in tetrachlorethylene.

\section{RESULTS}

In general, the heart valve preparations showed good localization of enzyme in the nerve fibres, but minor damage had occurred in a few cusps during processing. Usually this was due to kinking 
TABLE

Degeneration in Heavily Myelinated Fibres (in valve cusps or chordæ)

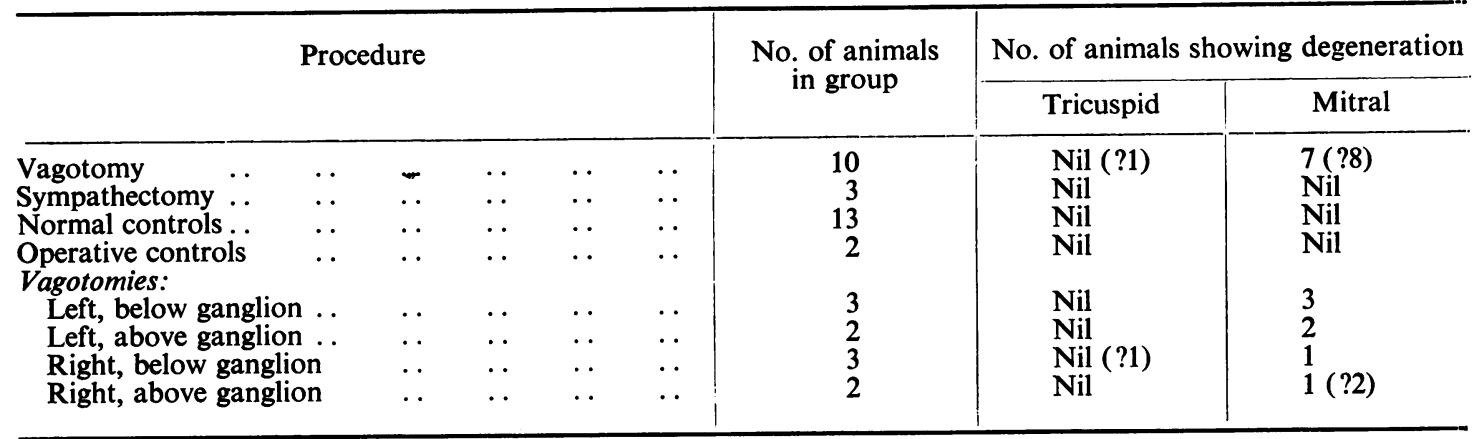

or folding of the tissue, and occasionally traumatic artefacts of the nervous elements ensued. With care, however, these artefacts could be distinguished from genuine degenerative phenomena and their association with tissue folds recognized. Confirmation that one's assessment was reliable was obtained from the control series, in which no evidence of degenerating myelinated fibres was noted.

The degenerative vesicles observed when medullated fibres are involved eclipse in size the vesicles seen when beaded nerve fibres are degenerating (Williams, 1963b). Consequently in most cases it is possible to make precise numerical statements concerning the myelinated fibres affected. The Table summarizes the results obtained: since examination of all the control preparations failed to reveal a single equivocal result, it is likely that the two findings queried in the Table represent positive degeneration.

Following unilateral cervical sympathectomy with total or subtotal stellatectomy, no abnormality was detected in the cuspidal myelinated fibres, although many of the beaded fibres within the cusps were affected. The number of sympathectomies carried out was smaller than desired, and this reflects the difficulties encountered in exposing and cleaning the stellate ganglion of a small animal without puncturing vital structures to which the ganglion adheres, namely the subclavian artery and cervical pleura. On account of the limited access, it was possible on only one occasion to be certain that the entire stellate complex had been extirpated.

The results in the vagotomy series provided a sharp contrast with the negative findings in both normal and sympathectomized animals. Following unilateral section of the vagus nerve a short distance below, or distal to, its inferior ganglion, degenerating myelinated fibres were identified in the majority of cases within the mitral valve and its chordæ. When the operation was carried out on the left side the degeneration was observed with greater consistency.

Unilateral division of the vagus nerve immediately below the jugular foramen and above the inferior ganglion again led to degeneration of the fast-conducting fibres in the mitral valve. In this group, as in the former, degeneration of the myelinated fibres was more evident after vagotomies carried out on the left side.

The acetylcholinesterase-positive vesicles that were interpreted as being degenerative phenomena were observed in the bodies of cusps or in the chordæ tendineæ (Fig. 1B). Sometimes they appeared as one or two large ellipsoidal or ovoid bodies; alternatively they presented as a chain of more moderately-sized vesicles. "Ghost" images of myelinated nerve strands, sometimes possessing irregular swellings along parts of their course, supplied confirmatory evidence of the type of nerve fibre involved.

\section{Discussion}

These experimental observations have been limited to subprimate material, but it is generally agreed that investigations carried out on experimental animals can provide useful clues about neurological mechanisms in man. Additional studies using primate material are receiving priority. 
From the absence of myelinated fibre degeneration after division of sympathetic fibre pathways to the heart, the tentative conclusion is reached that the sympathetic trunk is not the route taken by the nerve fibres in question, unless they travel in the thoracic cardiac nerves. Dissections of guinea-pigs have shown that a large proportion of the thoracic cardiac sympathetic nerves would have been destroyed when the stellate ganglion was extirpated (unpublished observation). Since tracheal intubation could not be performed successfully on guinea-pigs, the thoracic cardiac nerves could not be divided by a thoracic approach.

In the light of results from the vagotomy series it appears that the fast-conducting nerve fibres observed in the mitral valve take the vagal route, and that the left vagus nerve may carry the majority of these fibres. In addition, there is evidence that some or all of these axons of large diameter traverse the vagus without the intervention of cell bodies or synapses in the inferior ganglion. Further investigations will be necessary to decide whether they arise from cell bodies within the central nervous system or outside it but at a higher level than the inferior ganglion.

Though the possibility that the fast-conducting cuspidal fibres may be efferent has not been ruled out, it is suggested as a hypothesis that they are proprioceptive to the chordæ tendineæ and papillary muscles, and may possibly assist in a timing device. It is worth recalling that the only sensory pathway acknowledged to have all its cell bodies within the central nervous system is the proprioceptive component of the trigeminal nerve. Do proprioceptor fibres concerned with involuntary muscle also have their cell bodies located within the central nervous system?

\section{SUMMARY}

Degeneration experiments were carried out on guinea-pigs to determine the extracardiac course of the axons of large diameter $(6-8 \mu)$ which pass through the mitral valve to reach the chordæ tendineæ.

Unilateral cervical vagotomy carried out above or below the inferior vagal ganglion resulted in degeneration of these heavily myelinated fibres. These nervous elements did not degenerate after cervical sympathectomy or stellatectomy, nor were they degenerating in any of the control animals.

It was concluded that some or all of these fast-conducting fibres take the vagal route to the heart, and that some or all of their cell bodies are at some point cranial to the inferior vagal ganglion.

It is suggested that the nerve fibres in question may provide a proprioceptive pathway from the chordæ tendineæ and their papillary muscles. The possibility that the cell bodies of these axons lie within the central nervous system should be considered.

I appreciate the advice of Professor G. A. G. Mitchell, and thank Mr. P. Howarth for the photomicrography.

\section{REFERENCES}

Champy, C. (1959). Modifications de la technique de Champy au tétraoxyde d'osmium-iodure de potassium. Résultats de son application à l'étude des fibres nerveuses. C.R. Soc. Biol. (Paris), 153, 939.

Coupland, R. E., and Holmes, R. L. (1957). The use of cholinesterase techniques for the demonstration of peripheral nervous structures. Quart. J. micr. Sci., 98, 327.

Koelle, G. B., and Friedenwald, J. S. (1949). A histochemical method for localizing cholinesterase activity. Proc. Soc. exp. Biol. (N.Y.), 70, 617.

Williams, T. H. (1962). "Spreading factor," used before fixation, as an aid to cholinesterase localization. J. Histochem. Cytochem., 10, 435.

(1963a). Experimental studies of heart valve innervation. A preliminary report. J. Anat. (Lond.), $97,615$.

- (1963b). Terminal axonal degeneration visualized by a cholinesterase method. J. Anat. (Lond.), $97,625$.

(1964). Mitral and tricuspid valve innervation. Brit. Heart J., 26, 105. 